\title{
Welding Force Control of a Servo Gun (May 2017)
}

\author{
Ashwin Joshi ${ }^{1}$, Hrishikesh Lele ${ }^{2}$, Piyush Dongre ${ }^{3}$, Prof S.B. Somani ${ }^{4}$ \\ Student, Electronics and Telecommunication, MIT College of Engineering, Pune, India ${ }^{1,2,3}$ \\ Professor, Electronics and Telecommunication, MIT College of Engineering, Pune, India ${ }^{4}$
}

\begin{abstract}
This paper shows the implementation of a system to control the force of a servo gun while welding using a Programmable Logic Controller [PLC], a servo motor and a servo drive. The system depends on the software provided by Rockwell i.e. Ultraware to control the servo motor through the servo drive. By controlling the welding force we can improve the quality of the weld and hence the efficiency will also increase.
\end{abstract}

Keywords: PLC: Programmable Logic Controller, SCADA: Supervisory Control and Data Acquisition, Squeeze and Hold time, OPC server.

\section{INTRODUCTION}

Welding is a processes used to combine non-metallic and metallic materials, by applying heat or a combination of both at a specific temperature. Most welding procedures require heat and pressure although some procedures require only extreme pressure. Welding is a very critical part on the mechanical assemblies. Resistance Spot welding is a process where metal surfaces which are in contact are joined by heat obtained from resistance to electric current. Typically the size of the metal sheets used during welding is $0.5 \mathrm{~mm}$ to $3 \mathrm{~mm}$ thick. In earlier days Spot Welding was done using the pneumatic cylinders which will move the mobile arm of the welding gun. But these systems didn't have any control on the force applied. Hence, to control the force better versions came into existence which included the use of PLC. The current supplied by the drive to the motor to move the welding gun electrodes is a critical parameter which decides the amount of force generated.

\section{Why servo Mechanism?}

Time has put a lot of pressure on the speed of manufacturing, accuracy and quality. As the manufacturing technology changed, the production shifted from Batch manufacturing to Line manufacturing. In Line manufacturing all the processes of manufacturing are particular component are in cascade. The related machines are physically located in a close proximity to minimize the transit time.Many times it is required that the different types of parts are manufactured at the same time one after another i.e. if the first part is a door of car model 1 , then the second can be door of car model 2, again of model 1 and so on. This required fast changing of the process parameters.The requirement of the speed, accuracy and the flexibility in welding is fulfilled by using electrical Servo motor operated welding machines. Electrical parameters are relatively easy to control and monitor. Once the Servo drive parameters are set then there are very less chances that the drive will show fluctuations in those parameters.

\section{REVIEW OF RELATED LITERATURE}

The research carried out by Aravindan Arumugam and Abdul A Baharuddin has introduced electrode force as a control parameter. The electrode force during welding can be controlled with the use of servomechanism. Decreasing the electrode force during welding facilitates the initiation of spot weld growth earlier in the weld cycle which in turn produces bigger weld diameter and stronger weld strength. The opposite was noticed when electrode force was increased during the weld cycle. Furthermore decreasing the electrode fore during welding produced a button pull-out failure and increasing the force produced an interfacial weld failure. [2]

The electrode force affects the heat generation by controlling the resistance during the welding process. During the squeeze cycle, the electrode force which is used to bring the metal sheets into contact influences the contact resistance between the sheets or also known as faying surfaces. The contact resistance stems from the presence of roughness on the contact surfaces or an additional layer between contact surfaces. Contact resistance can be increased by reducing electrode force which will reduce the contact area at the faying surfaces and increase the current density.This will produce higher heat generation and increases the rate of melting of material during spot welding for a given welding current and weld time [3]. 
During the weld cycle, electrode force influences the dynamic resistance, which produces the Joule heating, required for spot weld growth. The dynamic resistance during RSW is a result of the sum of the bulk resistance, constriction resistance and film resistance and dominance of each resistance may change during the welding sequence [4].

The effect of pressure on the resistance spot weld should be carefully considered. The primary purpose of pressure is to hold the parts to be welded in intimate contact at the joint interface. This action assures consistent electrical resistance and conductivity at the point of weld. The tongs and electrode tips should not be used to pull the work pieces together. The resistance spot welding machine is not designed as an electrical " $C$ " clamp! The parts to be welded should be in intimate contact before pressure is applied. Proper pressures, with intimate contact of the electrode tip and the base metal, tend to conduct heat away from the weld. Higher currents are necessary with greater pressures and, conversely, lower pressures require less amperage from the resistance spot welding machine. This fact should be carefully noted, particularly when using a heat control with the various resistance spot welding machines. [1]

Resistance spot welding depends on the resistance of the base metal and the amount of current flowing to produce the heat necessary to make the spot weld. Another important factor is time. In most cases several thousand amperes are used in making the spot weld. Such amperage values, flowing through a relatively high resistance, will create a lot of heat in a short time. To make good resistance spot welds, it is necessary to have close control of the time the current is flowing. Actually, time is the only controllable variable in most single impulse resistance spot welding applications. Current is very often economically impractical to control. It is also unpredictable in many cases. [1]

\section{SYSTEM DESIGN}

A programmable Logic Controller is a microcontroller that continuously monitors the state of input devices and takes actions based upon a custom program to control the state of the output devices.Almost any production line, machine function, or a process can be greatly improved using this type of control system. However, the biggest benefit in using a PLC is the ability to change and execute the operation or process while collecting and communicating vital information. Servo Motor helps in controlling the commands fed at the input of the drive by the controller. Such commands include Position command, Velocity command, and Current command. Motor receives a pulse width and a frequency as an input from the drive which is converted to deliver the desired input command. Motor basically helps in driving the Welding gun. The Servo Drive gets its commands from the PLC and in turn it controls the Servo Motor. The servo drive can control the welding force that is applied during the welding process. The rotary motion of the servo motor is converted to linear motion using a ball screw mechanism and this motion is used to control the force being applied during the welding process. The process has 3 stages, viz. Home position (a reference position), Close position (position before the welding process actually starts) and Open position (position between Home and the Close position). When the mobile arm of the welding gun reaches the close position the drive performs the over-ride operation and then the welding current is applied. The time for which the welding current should be applied is decided by the Weld Controller. The main task of the weld Controller is to control the "Squeeze time" and the "Hold time". The drive parameters (velocity, current and position) are controlled using a software called Ultraware.

\section{FIGURES}

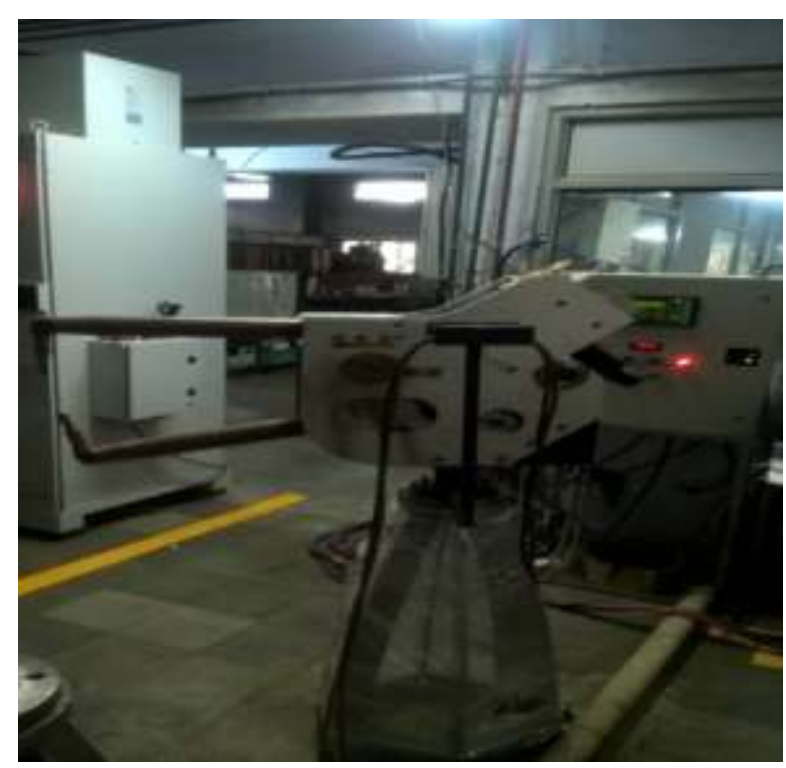

Fig 1. The Welding Gun 
Vol. 6, Issue 4, April 2017

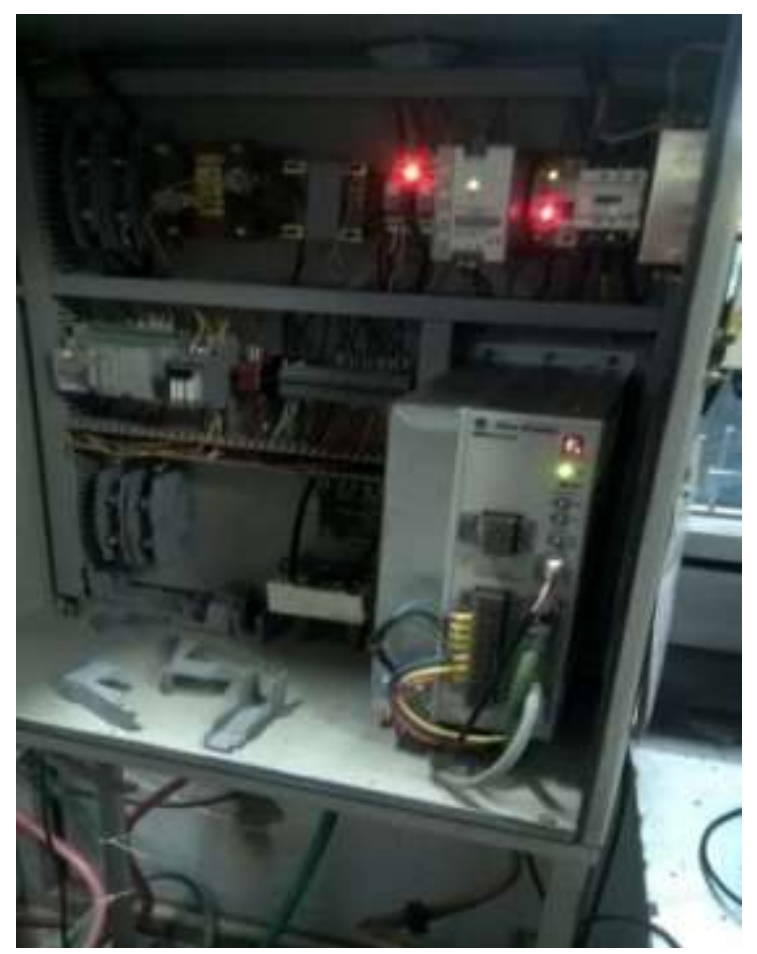

Fig 2. The Welding System Control Panel

\section{COMPLEXITIES INVOLVED}

Precise position control - This is required as the servo controller has to change the mode from position to current exactly at a point of contact of Gun arm with the sheets.1) The power required to go from open position to close position is less as compared to the pneumatic system \& 2) The electrodes don't hit against each other with a huge force as in the pneumatic system and hence reducing the noise as well as the wear and tear of the electrode tips. Thus precise position control is one of the most important parameter in welding.

While welding, the most important aspect is the application of the required force. The strength of the nugget depends on the application of the force and for how much time the force is applied. The larger the diameter of the nugget the greater it's strength. But a compromise is to be made because over-spilling or expulsion can occur if force applied is greater than required. Applying too much force for duration greater than required will cause expulsion which is not desired. So to avoid expulsion controlling the force is very important and hence turns out to be a very critical part of this system.Because of welding environment, the atmosphere around control system has lot of electrical noise. Grounding and cable lying are critical.

\section{CONCLUSION}

Spot welding using a welding gun mounted on the robot arm is widely used for large scale production mainly in automotive industries where it is difficult to carry out manual welding due to the complexity of the weld profiles and the huge parts. The cost of installation of the robots with higher degrees of freedom, with its necessary accessories and also its complex application makes it only suitable for mass production where the initial capital cost and running cost must be balanced over the life of the product. In the other method, where a stationary spot welding gun is used and the robot is moving the part, the cost of installation is reduced considerably. A 4-axis robot also can be used to perform this application which makes it suitable for simple welding application. It will have all the advantages of using a robot such as increased quality and better consistency etc. This method can only be used for simple application which doesnot involve any complex welding parts such as in the automotive industries.

\section{FUTURE SCOPE}

The drive parameters can also be controlled from a SCADA. This gives an intra industry access to the parameters with a simple interface. The data exchanged by the controller with its peripherals can also be monitored from an internal web server available in the programmable logic controllers. The access to this server can be wired or wireless. The server can be a cloud server, an OPC server etc. 
Near future will also see the intelligent welding guns with self-improvising capabilities. These systems will eliminate complex architectures, tiresome designing etc. And the welding gun on its own will monitor itself. This will eliminate human interference and save a lot of man hours. Technologies like Internet of things, Machine to Machine communication are creating a positive impact on the automotive sector line.

$\mathrm{M} 2 \mathrm{M}$ communication will give a very big platform for monitoring the welding process in automotive sectors. M2M will allow all the machines to communicate with each other and take wiser, smarter and faster decisions than the current systems.

\section{ACKNOWLEDGEMENT}

We thank Prof. S. B. Somani for his valuable guidance forthe paper. We are grateful to Mr. Anil Velankar and Mr. Milind Lele for their persistent support in the pragmatic issues while designing the welding system. Our gratitude to Prof Komati whose involvement in our project was very crucial and important.

\section{REFERENCES}

[1] Miller handbook for Resistance Spot Welding Papers Presented at Conferences:

[2] Effect of Force Control during Spot Welding on Weld Properties, AravinthanArumugam\& Abdul Baharuddin.

[3] P S Wei and T H Wu, "Electrical contact resistance effect on resistance spot welding", International Journal of Heat and Mass Transfer, 55, 2012, pp 3316-3324.

[4] W.Tan, Y Zhou, H W Kerr and S Lawson, "A study of dynamic resistance during small scale resistance spot welding of thin Ni sheets", Journal of Physics D:Applied Physics, 37, 2004, pp 1998 -2008.

[5] A Aravinthan and C. Nachimani, "Analysis of spot weld growth on mild and stainless steel", Welding Journal, 90, 2011, pp 143-147.

[6] S.Aslanlar, A.Ogur, U.Ozsarac and E.Ilhan.E, "Effect of welding current on mechanical properties of galvanized chromed steel sheet in electrical resistance spot welding", Materials and Design, 28, 2007, pp 2-7.

[7] M.Pouranvari and S.P.H Marashi, "Factors affecting mechanical properties of resistance spot welding", Materials Science and Technology, 261, 2010, pp 1137-1144.

[8] X Zhang, G Chen, Y Zhang and X Lai, "Improvement of resistance spot weld ability for dual-phase (DP600) steel using servo gun", Journal of Materials Processing Technology, 2009, pp 2671-2675.

[9] B H Chang and Y Zhou, "Numerical study on the effect of electrode force in small-scale resistance spot welding", Journal of Materials Processing Technology, 139, 2003, pp 635-641.

[10] MicroLogix 1400 Programmable Controllers User ManualBulletin 1766 Controllers and 1762 Expansion I/O.

[11] MicroLogix 1400 Programmable Controllers Reference ManualCatalog Numbers 1766-L32BWA, 1766-L32AWA, 1766-L32BXB, 1766L32BWAA, 1766-L32AWAA, 1766-L32BXBA.

[12] Ultraware Software User ManualCatalog Number 2098-UWCPRG

[13] SLC 500 Instruction Set Reference ManualCatalog Numbers 1747-L20x, 1747-L30x, 1747-L40x, 1747-L511, 1747-L514, 1747-L524, 1747L531, 1747-L532, 1747-L533, 1747-L541, 1747-L542, 1747-L543, 1747-L551, 1747-L552, 1747-L553. 